\title{
The Use of Advanced Optical Measurement Methods for the Mechanical Analysis of Shear Deficient Prestressed Concrete Members
}

\author{
K. De Wilder ${ }^{1), *}$, G. De Roeck ${ }^{2)}$, and L. Vandewalle ${ }^{1)}$ \\ (Received November 24, 2015, Accepted February 26, 2016, Published online March 18, 2016)
}

\begin{abstract}
This paper investigates on the use of advanced optical measurement methods, i.e. 3D coordinate measurement machines (3D CMM) and stereo-vision digital image correlation (3D DIC), for the mechanical analysis of shear deficient prestressed concrete members. Firstly, the experimental program is elaborated. Secondly, the working principle, experimental setup and corresponding accuracy and precision of the considered optical measurement techniques are reported. A novel way to apply synthesised strain sensor patterns for DIC is introduced. Thirdly, the experimental results are reported and an analysis is made of the structural behaviour based on the gathered experimental data. Both techniques yielded useful and complete data in comparison to traditional mechanical measurement techniques and allowed for the assessment of the mechanical behaviour of the reported test specimens. The identified structural behaviour presented in this paper can be used to optimize design procedure for shear-critical structural concrete members.
\end{abstract}

Keywords: experimental mechanics, prestressed concrete, coordinate measurement machine, stereo-vision digital image correlation.

\section{Introduction}

Despite the long-established and worldwide research effort, a widely accepted theory for determining the shear capacity of a structural concrete member remains open for discussion (Balázs 2010; Collins 2010). This can be mainly attributed to the complex nature of shear in structural concrete. Indeed, after the occurrence of inclined cracking, various shear transfer mechanisms are activated (Jeong and Kim 2014). The aforementioned mechanisms are interrelated and highly susceptible to various parameters such as the geometry, the amount of prestressing, material properties, the amount and type of shear and longitudinal reinforcement and the loading conditions. As a consequence, numerous analytical modelling approaches can be found in literature. An overview of recent approaches to shear in structural concrete elements can be found in Fédération Internationale du Béton (fib) (2010).

\footnotetext{
${ }^{1)}$ Department of Civil Engineering, Building Materials and Building Technology Section, KU Leuven, 3001 Heverlee, Belgium.

*Corresponding Author;

E-mail: kristof.dewilder@bwk.kuleuven.be

${ }^{2)}$ Department of Civil Engineering, Strucutral Mechanics Section, KU Leuven, Kasteelpark Arenberg 40, Box 2448, 3001 Heverlee, Belgium.

Copyright $($ The Author(s) 2016. This article is published with open access at Springerlink.com
}

The on-going debate on how to deal with shear in structural concrete members is also reflected by current codes of practice (European Committee for Standardization 2004; Canadian Standards Association 2004; American Concrete Institute 2011) which propose different design provisions resulting in varying design shear capacities and take factors affecting the shear capacity into account in a different way. Due to our incomplete knowledge and the brittle failure modes typically associated with shear, current codes of practice generally propose highly conservative shear provisions, specifically in the case of prestressed concrete elements (Nakamura et al. 2013). For the design of structural concrete members, these design equations lead to excessive material usage and corresponding construction costs. Reversely, using current codes of practice to determine the shear capacity, existing concrete structures are often found to be unable to withstand the applied service loads whereas no structural problems are reported in reality (Valerio et al. 2011; Lantsoght et al. 2013).

Improving analytical modelling approaches for shear in structural concrete members thus remains of utmost importance to optimize the design and analysis of structural concrete elements. A prerequisite for developing suitable models is a clear understanding of the actual mechanical behaviour observed during experimental tests. Traditional measurement techniques, i.e. linear variable differential transformers (LVDTs) or demountable mechanical strain gauges (DEMEC), usually provide limited test data in one or two directions. If the actual mechanical behaviour is to be understood, more elaborate experimental data is required. This paper therefore investigates on the use of advanced 
optical measurement methods, i.e. 3D coordinate measurement machines (CMMs) and Stereo-vision digital image correlation (3D DIC), for the mechanical analysis of sheardeficient structural concrete elements. The main focus in this paper will be on prestressed concrete beams. Firstly, the experimental program is elaborated. Secondly, the adopted measurement methods are presented and their corresponding setup is described. Thirdly, the experimental results are presented including the results of the precision assessment of the measurements and the full-scale experimental results. Finally, the mechanical behaviour of the reported test beams is investigated based on the acquired measurement data and compared to current modelling approaches found in codes of practice.

\section{Experimental Research}

\subsection{Geometry and Materials}

Nine test specimens were constructed and labelled with the descriptive letter $B$ followed by a number ranging from 101 to 109. All specimens were characterized by an Ishaped cross section, were $7000 \mathrm{~mm}$ long, $630 \mathrm{~mm}$ high. The flange width was equal to $240 \mathrm{~mm}$ whereas the web width was $70 \mathrm{~mm}$ wide. All specimens were prestressed using 8 or 4 seven-wire strands (nominal diameter $12.5 \mathrm{~mm}$ ) at the bottom and two seven-wire strands at the top (nominal diameter $9.3 \mathrm{~mm})$. The initial strain given to each prestressing strand was $7.5 \times 10^{-3} \mathrm{~mm} / \mathrm{mm}\left(\sigma_{p 0}=1488 \mathrm{MPa}\right)$ for specimens B101-B103 and B107-B109 whereas the stress level $\sigma_{p 0}$ in the strands of beams B104-B106 was equal to $750 \mathrm{MPa}$ (initial strain equal to $3.8 \times 10^{-3} \mathrm{~mm} /$ $\mathrm{mm})$. Shear reinforcement was provided in six specimens consisting of open single-legged stirrups with a nominal diameter of $6 \mathrm{~mm}$ (center-to-center distance equal to $150 \mathrm{~mm}$ ). To avoid splitting failure at the end of each specimen due to the gradual development of the prestressing force over the member's height, splitting reinforcement was provided in each specimen (nominal diameter $8 \mathrm{~mm}$, center to center distance equal to $50 \mathrm{~mm}$ ). An overview of the geometry of the reported test specimens is given in Figs. 1a to $1 \mathrm{f}$.

A self-compacting concrete mixture, designed to have a characteristic cylindrical compressive strength $f_{c k}$ equal to $50 \mathrm{MPa}$, was used to cast each specimen. The concrete mixture consisted of cement CEM I $52.5 \mathrm{R}$ (16.0 wt \%), limestone gravel 2/12 (43.8 wt \%), sand 0/2 (26.5 wt\%), water (6.7 $\mathrm{wt} \%)$, limestone filler $(6.7 \mathrm{wt} \%)$ and a high-range water reducer $(0.3 \mathrm{wt} \%)$. The expected density of this mixture was equal to $2378 \mathrm{~kg} / \mathrm{m}^{3}$. Standardized tests were performed to determine the mean cylindrical compressive strength $f_{c m}$ as well as the mean cube compressive strength $f_{\text {cm,cube }}$. Moreover, the mean flexural tensile strength $f_{c t m} f l$ and the secant modulus of elasticity $E_{c m}$ were determined for each specimen. The testing procedures can be found in Bureau for Standardisation NBN (2009a, b, 2014) The results are presented in Table 1 . The age of each specimen at the day of testing is also indicated in the aforementioned Table 1.
Standard tensile tests were performed on the reinforcement bars to determine the mean yield stress $f_{y m}$, the modulus of elasticity $E_{S}$, the mean ultimate tensile strength $f_{t m}$ and the corresponding strain at failure $\epsilon_{s u}$. The same characteristics were adopted from the technical information provided by the manufacturer of the prestressing strands. The results are shown in Table 2.

\subsection{Experimental Setup}

All test specimens are subjected to a four-point bending test, schematically shown in Fig. 2. A force-controlled loading scheme was followed using a hydraulic press (Instron, maximum capacity $2.5 \mathrm{MN}$ ). The load exerted by the hydraulic press was transferred to two point loads using a steel transfer beam. The total load was applied at a rate equal to $0.250 \mathrm{kN} / \mathrm{s}$ (shear force rate $\dot{V}=0.125 \mathrm{kN} / \mathrm{s}$ ). The distance between both support points was equal to $5000 \mathrm{~mm}$. The distance outside the support points was therefore equal to $1000 \mathrm{~mm}$. This allowed the authors to investigate on the mechanical behaviour of shear in the presented test beams outside the length needed for the prestressing force to gradually develop over the member's height. The shear span $a$, i.e. the distance between the support point and the load point, was equal to $1600 \mathrm{~mm}$ (specimens B101, B104 and B107) or $2000 \mathrm{~mm}$ (B102-B103, B105B106, B108-B109). Given the geometry and reinforcement layout, this resulted in shear span-to-effective depth ratios $\left(\frac{a}{d}-\right.$ ratio) between 2.91 and 3.91. An overview of the investigated parameters per specimen is given in Table 3 .

\subsection{Adopted Measurement Methods 2.3.1 CCD-LED Coordinate Measurement Machine (CMM)}

As an optical motion tracking system, coordinate measurement machines [CMMs, also referred to as dynamic measurement machines (DMMs)] have proven to be an ideal tool for a wide range of applications, including biomechanical (Burg et al. 2013), automotive (Deconinck et al. 2004) and civil engineering applications (De Roeck et al. 2004; Sun 2007). The basic principle behind this technique is to determine the three-dimensional location of a discrete amount of points by means of triangulation. Here, two Krypton K600 CMM (Nikon Metrology, formerly known as Metris, Leuven, Belgium) systems were used for the experiment on specimen B101. The points of which the three-dimensional coordinates were to be determined were infra-red (IR) light emitting diodes (LEDs). In total 112 LEDs were used and each LED was placed onto an orthogonal grid covering both zones where a shear force occurred, refer to Fig. 3a, and was glued onto the concrete surface by using a thermoplastic adhesive. Since the LEDs were attached to the material underneath, the displacement of each LED, from which deformations can be derived, is the same as the material under investigation. The IR light emitted by each LED was seen by a camera unit consisting of three 2048 px charge-coupled device (CCD) line-element cameras, as shown in Fig. 3b. All LEDs were connected in series to a camera control unit which also acted as an interface between the cameras and the DAQ laptops. 


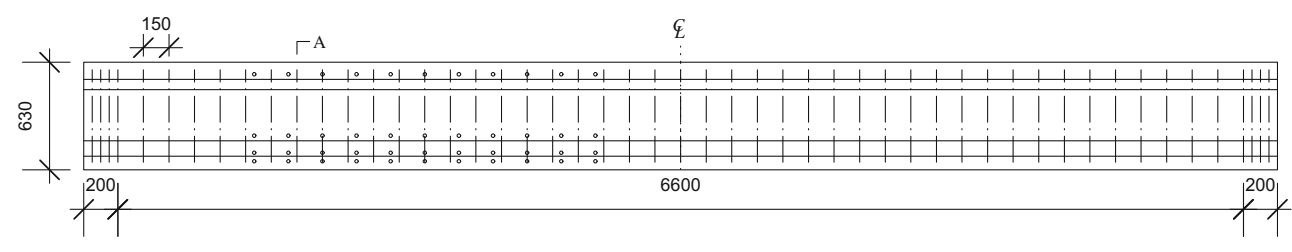

(a) B101-B102, B104-B105, B107-B108

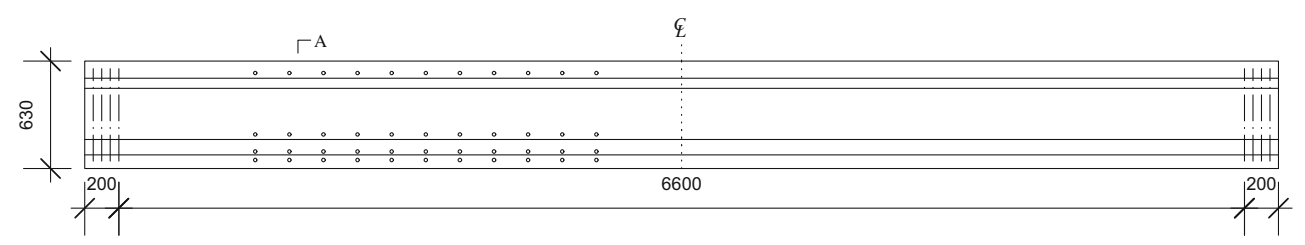

(b) B103, B106, B109

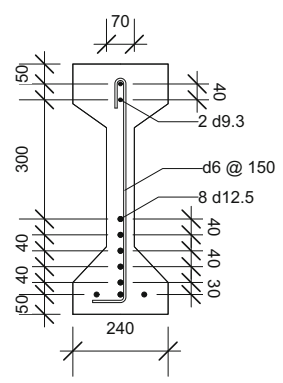

(c) B101-B102, B104B105

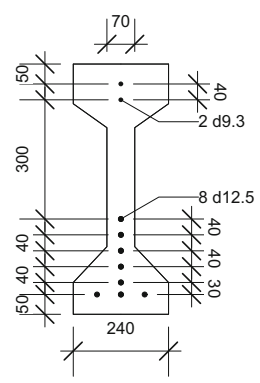

(d) B103

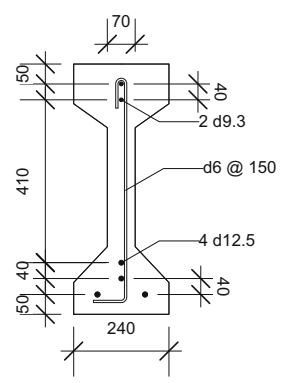

(e) B107-B108

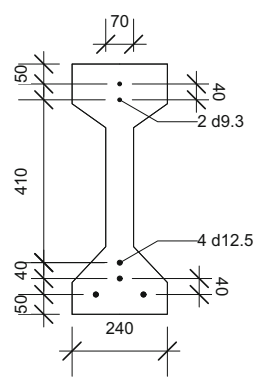

(f) $\mathrm{B} 109$

Fig. 1 Geometry and reinforcement layout of the reported test specimens: a, b Longitudinal drawings; c-f Cross sectional drawings.

Table 1 Concrete material properties for reported specimens.

\begin{tabular}{|c|c|c|c|c|c|}
\hline Specimens & $\begin{array}{c}f_{\text {cm,cube }} \\
(\mathrm{MPa}) \\
\left(\#^{*}, \mathrm{~s}^{* *}\right)\end{array}$ & $\begin{array}{c}f_{c m} \\
(\mathrm{MPa}) \\
(\#, \mathrm{~s})\end{array}$ & $\begin{array}{c}E_{c m} \\
(\mathrm{GPa}) \\
(\#, \mathrm{~s})\end{array}$ & $\begin{array}{l}f_{c t m, f l} \\
(\mathrm{MPa}) \\
(\#, \mathrm{~s})\end{array}$ & Age (days) \\
\hline B101-B103 & $87.1(8,6.8)$ & $77.5(5,10.7)$ & $43.4(3,2.3)$ & $5.8(6,0.6)$ & $28-233-393$ \\
\hline B104-B106 & $82.8(9,10.5)$ & $88.9(6,10.2)$ & $43.5(6,8.0)$ & $6.5(6,1.0)$ & $412-404-407$ \\
\hline B107-B109 & $74.6(9,9.6)$ & $89.3(6,14.2)$ & $42.2(6,4.6)$ & $5.7(6,1.1)$ & $428-424-412$ \\
\hline
\end{tabular}

* Number of tested specimens, ** Standard deviation.

Table 2 Reinforcement properties.

\begin{tabular}{c|c|c|c|c|c|c}
\hline Reinf. type & Type & $\begin{array}{c}d_{s} \\
d_{p}{ }^{*} \\
(\mathrm{~mm})\end{array}$ & $\begin{array}{c}E_{s} \\
E_{p} \\
(\mathrm{GPa})\end{array}$ & $\begin{array}{c}f_{y m} \\
f_{p 0.1 m} \\
(\mathrm{MPa})\end{array}$ & $\begin{array}{c}f_{t m} \\
f_{p m} \\
(\mathrm{MPa})\end{array}$ & $\begin{array}{c}\epsilon_{s u} \\
\epsilon_{p u} \\
(\%)\end{array}$ \\
\hline \hline Top prestress. reinf. & 7-wire & 9.3 & 198.0 & 1737 & 1930 & 5.20 \\
\hline Bot. prestress. reinf. & 7-wire & 12.5 & 198.0 & 608 & 636 & 5.20 \\
\hline Shear reinf. & Cold worked & 6.0 & 210.0 & 542 & 603 & 5.97 \\
\hline Splitting reinf. & Cold worked & 8.0 & 203.0 & 543 & 50 \\
\hline
\end{tabular}

* Subscript $p$ and $s$ denote properties of prestressing and conventional reinforcement types, respectively. 


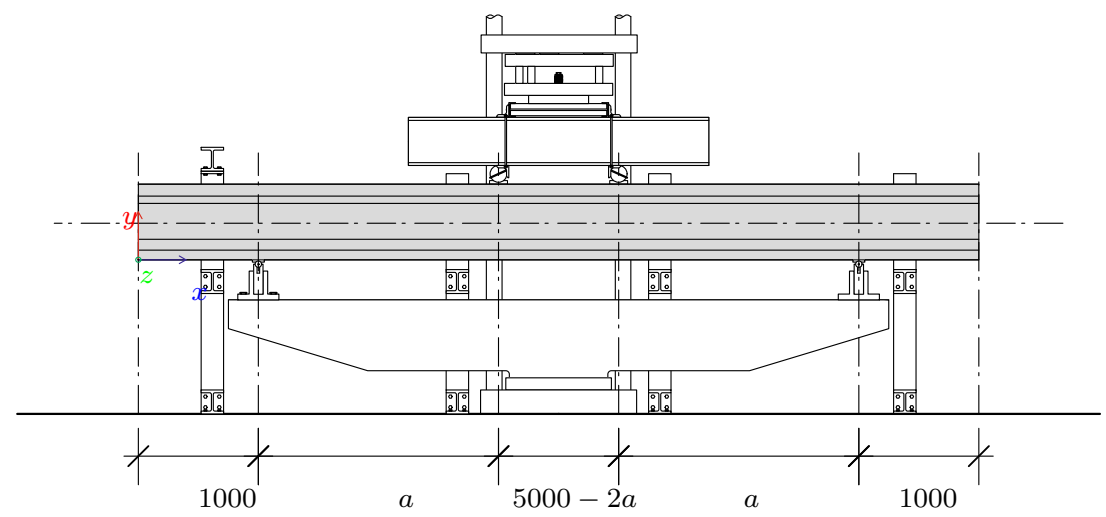

Fig. 2 Schematic representation of the experimental setup (note ( $x, y, z)$ denote Cartesian coordinates).

Table 3 Overview of the investigated parameters per specimen.

\begin{tabular}{c|c|c|c|c|c|c|c}
\hline Specimen & Type & $\begin{array}{c}\mathrm{d}^{*} \\
(\mathrm{~mm})\end{array}$ & $\begin{array}{c}\sigma_{p 0} \\
(\mathrm{MPa})\end{array}$ & $\begin{array}{c}a \\
(\mathrm{~mm})\end{array}$ & $\begin{array}{c}\frac{a}{d} \\
(-)\end{array}$ & $\begin{array}{c}\rho_{l}^{* *} \\
(-)\end{array}$ & $\begin{array}{c}\rho_{w}^{* * *} \\
\left(\times 10^{-3}\right)\end{array}$ \\
\hline \hline B101 & $\mathrm{I}$ & 511 & 1488 & 1600 & 3.13 & 0.0208 & 2.693 \\
\hline B102 & $\mathrm{I}$ & 511 & 1488 & 2000 & 3.91 & 0.0208 & 2.693 \\
\hline B103 & I & 511 & 1488 & 2000 & 3.91 & 0.0208 & 0 \\
\hline B104 & I & 511 & 750 & 1600 & 3.13 & 0.0208 & 2.693 \\
\hline B105 & I & 511 & 750 & 2000 & 3.91 & 0.0208 & 2.693 \\
\hline B106 & I & 511 & 750 & 2000 & 3.91 & 0.0208 & 0 \\
\hline B107 & I & 550 & 1488 & 1600 & 2.91 & 0.0097 & 2.693 \\
\hline B108 & I & 550 & 1488 & 2000 & 3.64 & 0.0097 & 2.693 \\
\hline B109 & I & 550 & 1488 & 2000 & 3.64 & 0.0097 & 0 \\
\hline
\end{tabular}

* Effective depth.

** Longitudinal reinforcement ratio $\frac{A_{s l}}{b_{w} d}$ with $A_{s l}$ area of longitudinal reinforcement and $b_{w}$ web width.

*** Shear reinforcement ratio $\rho_{w}=\frac{A_{s w}}{b_{w} s}$ with $\frac{A_{s w}}{s}$ the area of shear reinforcement per unit length.

To assess the accuracy (closeness of the measurement to the true value, related to systematic errors) and precision (the degree to which repeated measurements under unchanged conditions show the same results, related to random errors) of the CCD-LED system, a reference measurement was performed. During the aforementioned reference measurement, each coordinate of each LED was measured during $50 \mathrm{~s}$ at a measurement frequency of $20 \mathrm{~Hz}$. Typical results of the variation of each coordinate around its initial value $u_{i}$ (with $i=x, y, z$ ) for one LED are shown in Figs. 4a to 4c. The noise on the measurement data can assumed to be approximately normally distributed. Therefore, Figs. $4 \mathrm{~d}$ to $4 \mathrm{f}$ show the fitted normal probability density functions (PDF) of $u_{i}(i=x, y, z)$. The mean value and corresponding standard deviation are also indicated in the aforementioned figures.

Based on the coordinate measurements obtained during the aforementioned reference measurement, in-plane strain values (both horizontal $\epsilon_{x}$ and vertical $\epsilon_{y}$ ) can be derived between two consecutive LEDs. The standard deviation of the in-plane horizontal and vertical strain value, $s_{\epsilon_{x}}$ and $s_{\epsilon_{y}}$ can then be calculated as a function of the surface coordinates. The results are presented in Figs. 5a and 5b. From the aforementioned
Fig. 5a, it can be seen that the value of the standard deviation of the horizontal strain $s_{\epsilon_{x}}$ is well below the typical strain values occurring for concrete in compression (maximum compressive strain $\epsilon_{c u} \simeq 35 \times 10^{-4} \mathrm{~mm} / \mathrm{mm}$ ). Figure $5 \mathrm{~b}$ indicates that less precise measurements of the vertical strain are obtained near the top flange of the beam but good overall results are acquired in the web of the specimens. Indeed, the values of the vertical strain will primarily be used to assess the strain and thus stress levels in the shear reinforcement elements. Yielding of the shear reinforcement occurs at nearly $29 \times 10^{-4} \mathrm{~mm} / \mathrm{mm}$, refer to Table 2 whereas rupture occurs at a strain value equal to $273 \times 10^{-4}$. Therefore, the expected vertical strains are well outside the obtained noise levels. The variation of the derived strain values as a function of the surface coordinate is primarily due to the different relative positions of each IR LED with respect to the optical centre of the camera control units.

\subsubsection{Stereo-Vision Digital Image Correlation (3D-DIC)}

As an optical-numerical full-field measurement method, digital image correlation (DIC) has proven to be an ideal tool for a wide range of applications, including the identification 
of the mechanical material behavior through inverse modeling (Cooreman et al. 2007, 2008), structural health monitoring (Sas et al. 2012) and the study of the deformation characteristics of a wide range of materials (Ivanov et al. 2009; Van Paepegem et al. 2009; Srikar et al. 2016). During the testing of specimens B103-B109, the stereo-vision digital image correlation technique (3D-DIC) has been adopted
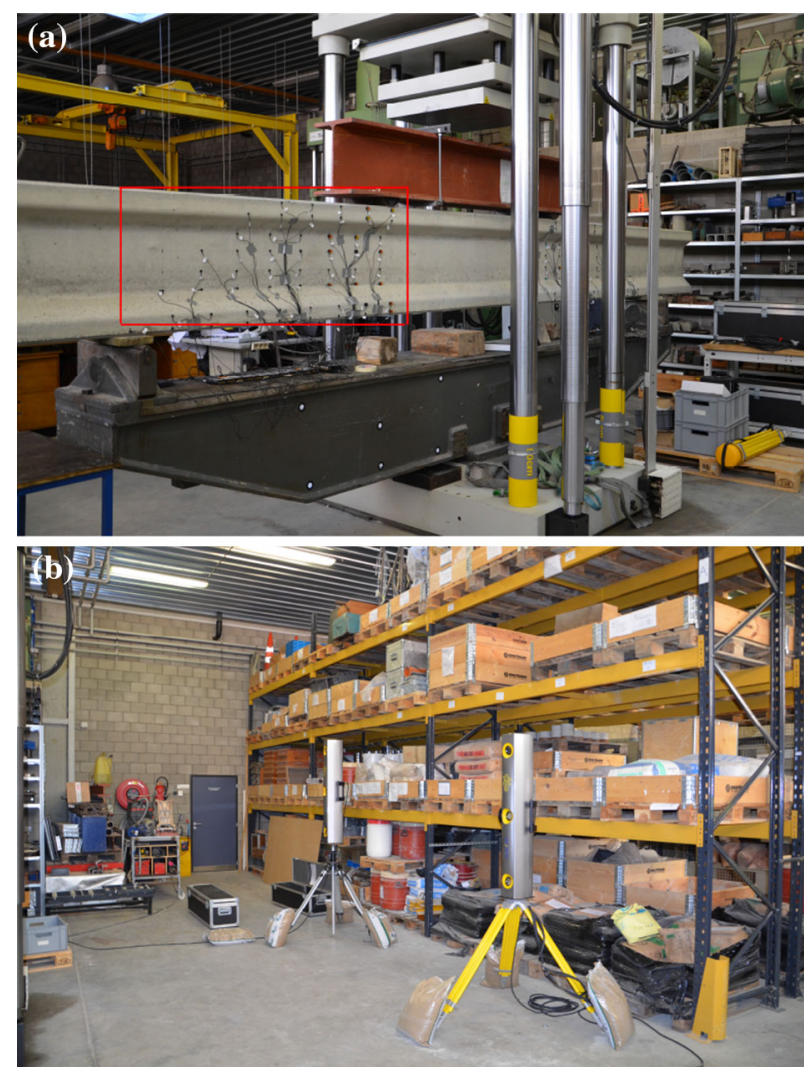

Fig. 3 Experimental setup for the adopted coordinate measurement machine (CMM): a IR LEDs (indicated with red rectangle); $\mathbf{b}$ Camera units mounted on tripod. to assess the displacements and deformations during the loading procedure. Stereo-vision implies the use of two cameras to allow for the reconstruction of the three-dimensional geometry and measurement of the three-dimensional displacements opposed to single-camera measurements which yield only two-dimensional data. The basic principle behind this technique is to calculate the displacements on the surface of an object by taking images of a random speckle pattern in undeformed and deformed state. As the speckle pattern is attached to the material underneath, the displacement and deformation of the speckle pattern is the same as the surface material of the object under investigation. To follow the displacement and deformation evolution during the full-scale experiments, a series of images of the object is made and the speckle pattern displacement and deformation in the series of images can be followed. The grey-value images of the speckle pattern are captured with a CCD camera. Similar to the CMM measurements, both zones where a shear force occurs were investigated using two DIC systems, each consisting of two cameras. This setup allowed for stereo-vision measurements. Both cameras of each DIC system take simultaneously a picture of the investigated object, in the following denoted as a frame. Each stereovision DIC system consisted of two 8-bit CCD cameras (AVT F201 B; 1628 px $\times 1236$ px resolution) with wideangle lenses (focal length equal to $12 \mathrm{~mm}$ ) mounted on a tripod. Each zone under investigation measured approximately $1500 \mathrm{~mm} \times 630 \mathrm{~mm}$. The cameras were located at a perpendicular distance of approximately $2700 \mathrm{~mm}$ from the web of the specimen. To ensure good lighting conditions and allow for small exposure times, two $500 \mathrm{~W}$ quartz iodine lamps were provided per investigated zone. The image acquisition rate of each camera was equal to $2 \mathrm{~Hz}$. All images were transferred to a desktop computer and synchronized with the analogue data of the hydraulic press (i.e. applied load and corresponding displacement). The experimental setup is depicted in Figs. 6a and 6b.
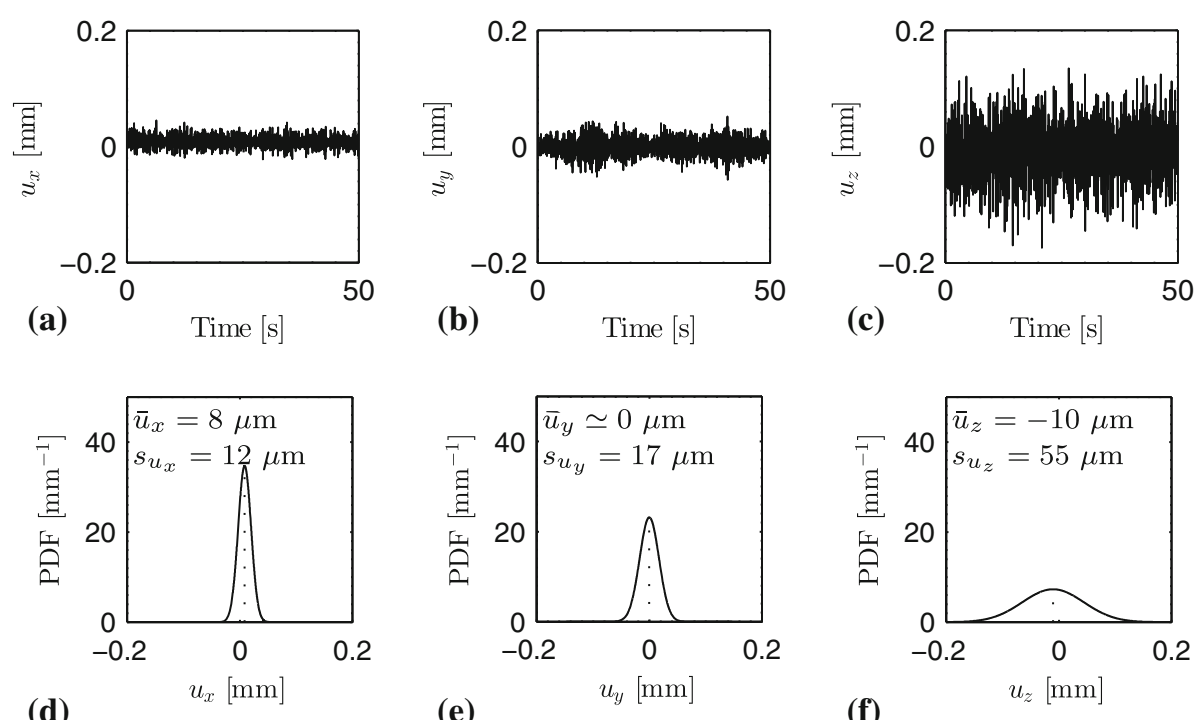

Fig. 4 Accuracy and precision assessment of the Krypton K600 CMM for the upper left LED (refer to Fig. 3a): a horizontal inplane displacement $u_{x}$; vertical in-plane displacement $u_{y}$; out-of-plane displacement $u_{z}$; fitted normal PDF for $\mathbf{d} u_{x} ; \mathbf{e} u_{y}$; f $u_{z}$. 

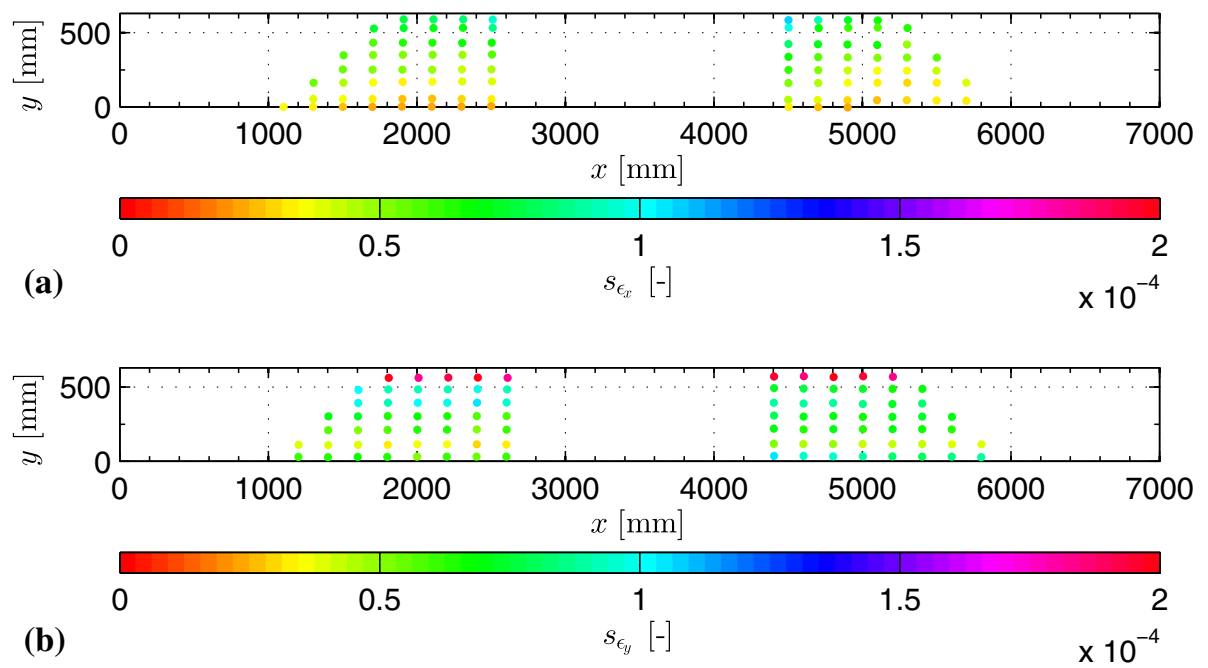

Fig. 5 Precision assessment of the adopted Krypton K600 CMM for the derived strain measurements: a standard deviation of the horizontal strain $s_{\epsilon_{x}}$ as a function of the location on the specimen; $\mathbf{b}$ standard deviation of the vertical strain $s_{\epsilon_{y}}$ as a function of the location on the specimen.

The analysis of the frames taken during the loading was done with specialized software. In this work, the in-house code MatchID (KU Leuven, Campus Ghent) (Lava et al. 2009, 2010, 2011; Wang et al. 2011) was used. To reveal the displacements and deformations of an object during an experiment, typically a square subset of $(2 M+1)$ pixels (px) from the undeformed image is taken and its location in the deformed image is traced. The principle of the stereo-vision DIC algorithm is clearly explained by Lava et al. (2011). Matching of two $(2 M+1) \mathrm{px}$ subsets in the undeformed image $\mathbf{F}\left(x_{i}, y_{j}\right)$ and deformed image $\mathbf{G}^{\mathrm{t}}\left(x_{i}, y_{j}\right)$ at a certain time $t$ (i.e. load step) is performed by adopting an optimization routine for a degree of similarity expressed by a correlation criterion. Here, the Zero Normalized Sum of Squared Differences (ZNSSD) correlation criterion was adopted. This correlation criterion is independent of scale and offset in lighting (Sutton et al. 2009) and is therefore the most suitable correlation criterion to yield accurate results, especially in the zones where the lighting conditions are difficult to control, i.e. transition zones between web and flange of the I-shaped specimens. The mathematical formalism is clearly explained in the reference work by Sutton et al. (2009).

Lecompte (2007) states that it has already been shown that the subset size is a critical parameter in the correlation process (Knauss et al. 2003). On the one hand it should be chosen small enough to allow for a reasonable linear approximation of the displacement field, within the region of the subset. On the other hand the subset size should not be chosen too small, to avoid correlation problems due to the non-uniqueness of the subset information content. This indicates the importance of an adequate speckle pattern for digital image correlation. From a solely black or white pattern, no valuable displacement information can be gathered so that the subset size should be larger than the speckle size. Destrycker (2012) states that to isolate the effect of the speckle pattern, there should be a way of applying the speckle pattern in a controlled way, e.g. controlling the
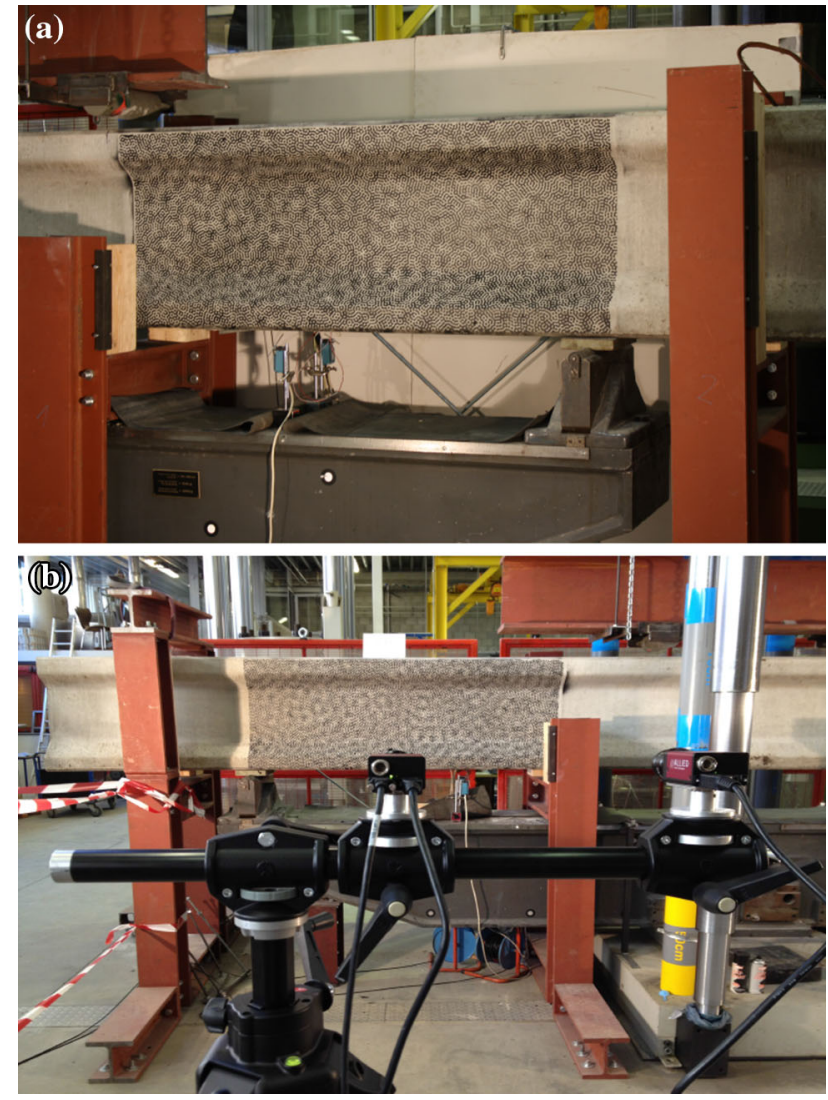

Fig. 6 Experimental setup for DIC measurements: a numerically generated speckle pattern applied onto specimen B104; b 8-bit CCD cameras mounted on tripod located at a perpendicular distance of $2700 \mathrm{~mm}$ from the web of the test specimens.

speckle size, the speckle size distribution, the grey value distribution and the actual colour of the black and white paint. Therefore, to be able to generate suitable DIC speckle patterns, a numerical technique recently proposed by Bossuyt (2012) was adopted. In his work, Bossuyt (2012) firstly 
defines two concepts which are used to assess the suitability of a speckle pattern for DIC measurements. Firstly, the autocorrelation peak sharpness radius of a pre-processed image of the considered pattern is proposed to quantitatively evaluate how a particular strain sensor pattern influences the sensitivity of a DIC measurement. Secondly, the autocorrelation margin is proposed to evaluate how that pattern influences the robustness of the DIC measurement. The former is related to the measurement precision whereas the latter is correlated to the measurement accuracy. Ideal patterns for DIC would combine a sharp autocorrelation peak with a well-defined autocorrelation margin. For simple patterns, these characteristics vary in direct proportion to each other. However, Bossuyt (2012) proposes a method based on morphological image processing and Fourier transform to synthesize a DIC pattern with wide autocorrelation margins even though the autocorrelation peaks are sharp. Such patterns are exceptionally well-suited for DIC measurements. A detail of the numerically generated speckle pattern is shown in Fig. 7a. The generated pattern is then applied onto each specimen where the DIC technique was used by adopting a heat-sensitive stencil printing technique which consists of three layers: a vinyl base layer, the inverse of the speckle pattern and a top protective heat-sensitive polypropylene layer. The printed speckles have a precalculated oversampling of at least five pixels in order to avoid aliasing effects in the obtained results due to the expected small magnitude of the displacement and deformation field. Given the camera sensor properties and the dimensions of the field of view, speckles with a diameter of nearly $5 \mathrm{~mm}$ were required. Obtaining

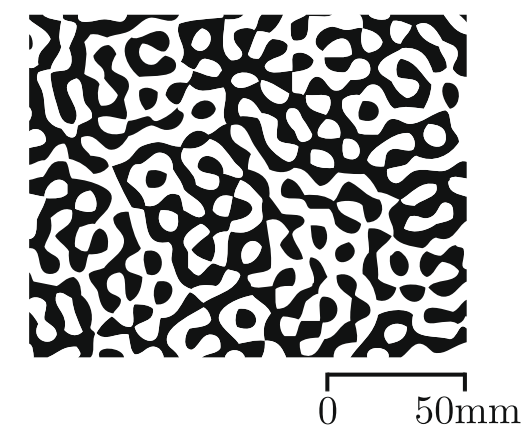

(a)

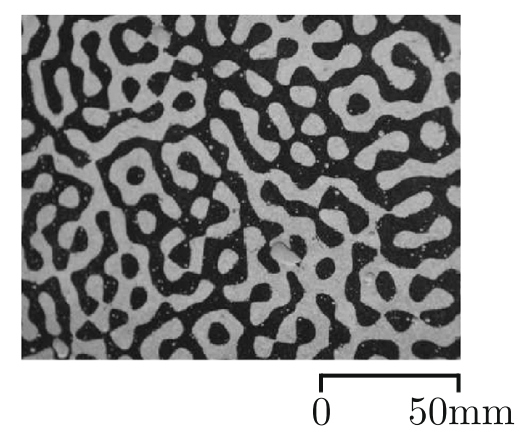

(b)

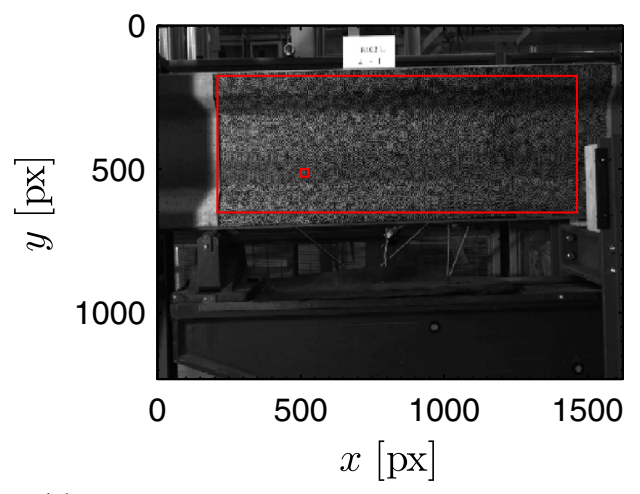

(c)

Fig. 7 a Detail of numerically generated speckle pattern; b Detail of the speckle pattern shown in (a) applied onto specimen B105; c indication of area of interest (AOI) and subset size in red for the left measurement field of specimen B103.

Table 4 Measurement settings for the DIC tests.

\begin{tabular}{|c|c|c|c|c|c|c|c|c|}
\hline & Unit & B103 & B104 & $\mathrm{B} 105$ & B106 & B107 & B108 & B109 \\
\hline Subset & $(p x)$ & 27 & 27 & 27 & 27 & 27 & 27 & 27 \\
\hline Step & (px) & 3 & 3 & 3 & 3 & 3 & 3 & 3 \\
\hline $\begin{array}{c}\text { Measurement } \\
\text { points }\end{array}$ & $(-)$ & 68327 & 67482 & 67819 & 70290 & 68843 & 68868 & 75864 \\
\hline $\begin{array}{l}\text { Temporal } \\
\text { resolution }\end{array}$ & (fps) & 2 & 2 & 2 & 2 & 2 & 2 & 2 \\
\hline $\begin{array}{l}\text { Camera } \\
\text { distance }\end{array}$ & $(\mathrm{mm})$ & 2700 & 2700 & 2700 & 2700 & 2700 & 2700 & 2700 \\
\hline Interpolation & $(-)$ & b.c.s. ${ }^{\dagger}$ & b.c.s. & b.c.s. & b.c.s. & b.c.s. & b.c.s. & b.c.s. \\
\hline \multicolumn{9}{|c|}{ Displacement } \\
\hline $\begin{array}{c}\text { Spatial } \\
\text { resolution }^{\mathrm{a}}\end{array}$ & $(\mathrm{mm})$ & 31.2 & 30.9 & 29.9 & 29.5 & 29.9 & 30.8 & 28.4 \\
\hline $\begin{array}{l}\text { In-plane } \\
\text { resolution }\end{array}$ & $(\mathrm{mm})$ & 0.018 & 0.019 & 0.034 & 0.027 & 0.020 & 0.021 & 0.023 \\
\hline $\begin{array}{c}\text { Out-of-plane } \\
\text { resolution }{ }^{\dagger}\end{array}$ & $(\mathrm{mm})$ & 0.125 & 0.120 & 0.165 & 0.167 & 0.147 & 0.149 & 0.152 \\
\hline
\end{tabular}

\footnotetext{
$\dagger$ Bicubic spline.
}

$\$$ Maximum mean value of the standard deviation of the in-plane horizontal and vertical displacement; mean value of the standard deviation of the out-of-plane displacement.

a Physical dimension of subset. 

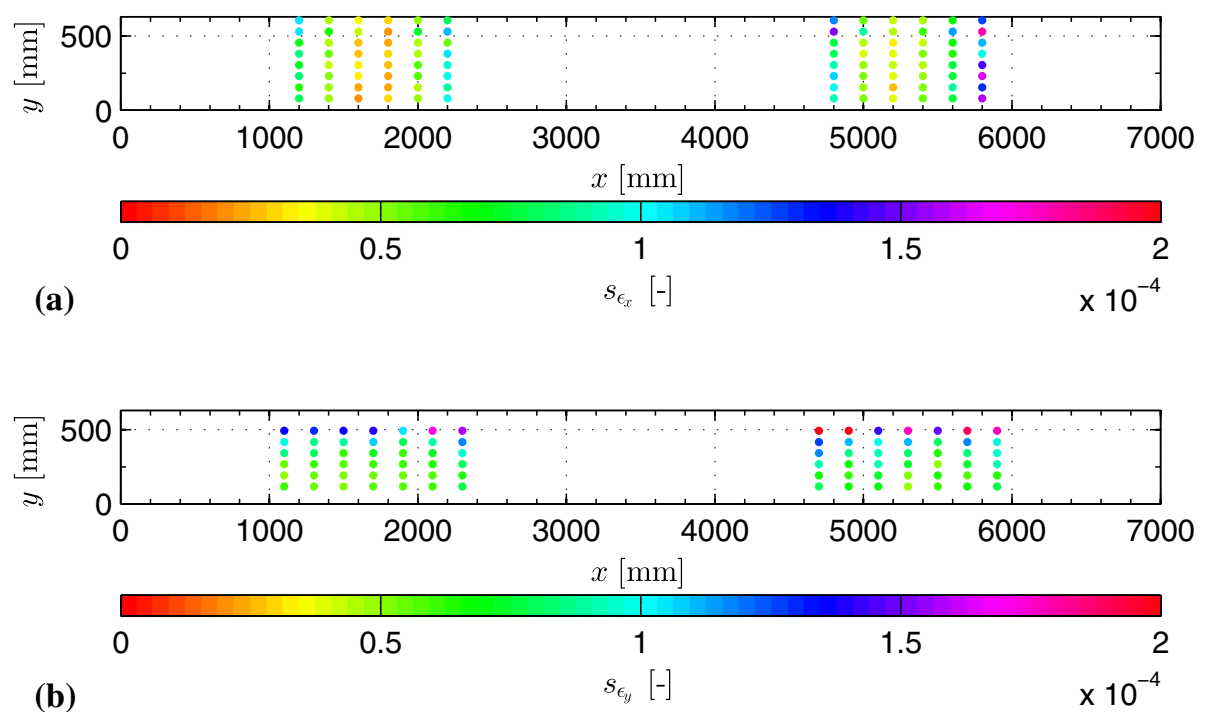

Fig. 8 Precision assessment of the adopted 3D DIC system for the derived strain measurements for specimen B103: a standard deviation of the horizontal strain $s_{\epsilon_{x}}$ as a function of the location on the specimen; $\mathbf{b}$ standard deviation of the vertical strain $s_{\epsilon_{y}}$ as a function of the location on the specimen.

large speckles is nearly impossible with traditional speckle techniques (i.e. spray painting). However, the adopted numerical technique allows for the generation of a speckle pattern tailored to the needs of the experiment. Figure $7 \mathrm{~b}$ shows the same detail as presented in Fig. 7a applied onto beam B105. Figure 7c shows the speckle pattern, area of interest and adopted subset size. Since full-field displacement data is readily available, Green-Lagrange strains can be easily derived from the aforementioned displacement data. Therefore, the displacement data is smoothed over a certain zone to damp out the effect of noise and local uncertainties. A bilinear plane can be fitted through the displacement values in the points around the center of the strain window.

To assess the precision of the 3D-DIC setup for the presented experiments, a number $(N=50)$ of reference images were taken prior to each test under a zero-loading condition. The subset size was taken equal to $27 \mathrm{px}$ whereas the stepsize was chosen equal to $3 \mathrm{px}$. Given the experimental setup, the physical dimension of 1 pixel approximated $1 \mathrm{~mm}$. The subset was allowed to undergo an affine transformation thus taking into account translation, rotation, shear and normal straining. As the displacements from one frame to another may be smaller than one pixel, the subset in the image of the deformed state is not likely to fit on the pixel grid and an interpolation method between the pixels is needed. Therefore, a bicubic interpolation scheme has been adopted in the MatchID software during the analyses. Additionally, Gaussian prefiltering $(5 \times 5$ px kernel size $)$ of the subset information was adopted as a low pass-filter to attenuate highfrequency signals and allow for proper interpolation. Based on the measured displacements $u_{i}$ (with $i=x, y, z$ ), GreenLagrange strains can be determined by means of bilinearquadrilateral smoothing of the displacement field. This method was adopted for the analyses of the frames during the loading procedure. For the purpose of assessing the precision, strains were derived directly from the displacement data with similar initial base lengths $L_{0}$ as the CMM and without smoothing of the displacement field to allow for a reasonable comparison between both adopted systems. The base length to determine the horizontal strains $L_{0}^{-}$was chosen approximately equal to $200 \mathrm{~mm}$ whereas the base length to determine vertical strains $L_{0}^{\mid}$was taken roughly equal to $75 \mathrm{~mm}$. An overview of the adopted DIC settings is presented in Table 4. Similar to the CMM system, Figs. $8 \mathrm{a}$ and $8 \mathrm{~b}$ present the standard deviation of the horizontal and vertical strain $s_{\epsilon_{i}}$ (with $i=x, y$ ) based on the $N$ pairs of reference images obtained from both DIC systems for specimen B103. Comparable results were found for the remaining specimens where the DIC technique has been adopted.

From the aforementioned Figs. $8 \mathrm{a}$ and $8 \mathrm{~b}$, it can be firstly seen that similar values for the standard deviation of both the horizontal and vertical strain are found if the data of the 3D DIC system is compared to the data obtained from the Krypton K600 system, refer to Figs. 5a and 5b. Secondly, it can be seen that less precise measurements of the horizontal strain $\epsilon_{x}$ occur near the edge of the area of interest, refer to Fig. 8a. This can be attributed to optical aberration effects near the edge of the field of view. However, the value of the expected strains during the loading procedure well exceed the presented values of the standard deviation of the horizontal strain. Thirdly, due to the shaded area near the transition between the top flange and the web, refer to Fig. 7c, less precise measurements of the vertical displacement are obtained resulting in less accurate vertical strain measurements near the top flange. However, vertical strains will primarily be investigated in the web of the specimens to assess the strain and stress levels in the shear reinforcement elements.

\section{Results and Discussion}

Figure 9a-c depict the experimentally observed load-displacement response curves of the presented test specimens. The onset of bending $(\circ)$ and diagonal $(\triangle)$ cracking is also 

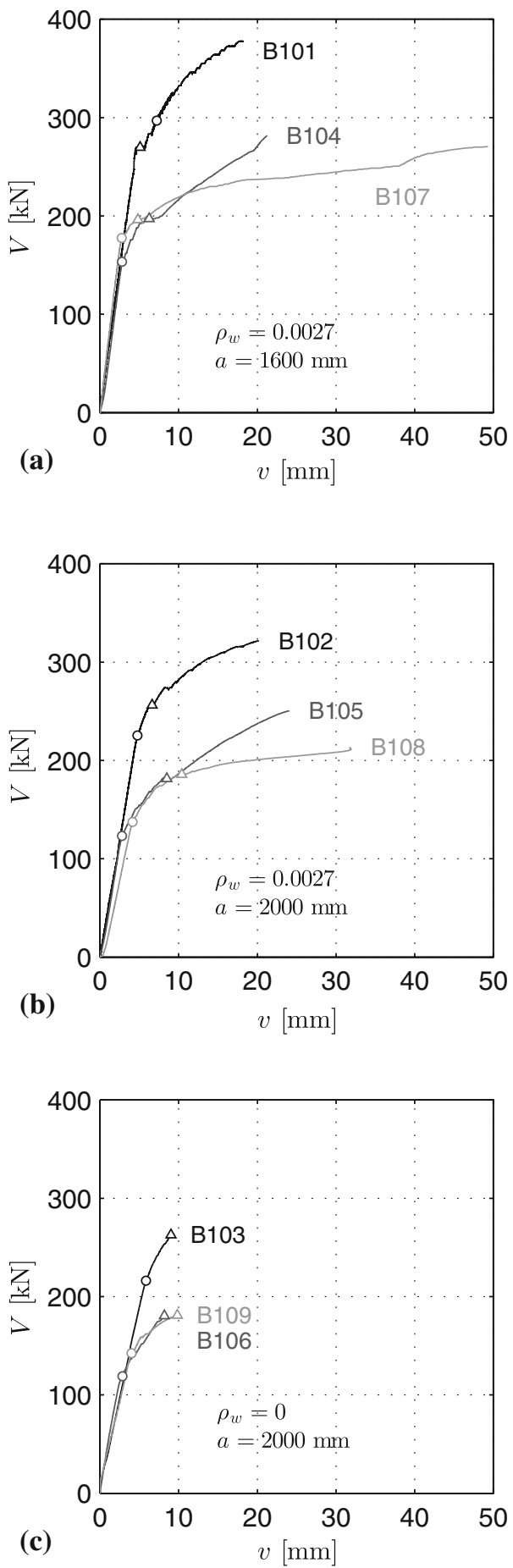

Fig. 9 Experimentally determined load-displacement response curves measured at $1200 \mathrm{~mm}$ from the support point: a specimens B101, B104 and B107; b specimens B102, B105 and B108; c specimens B103, B106 and B109 (note onset of bending and diagonal cracking indicated with (circle) respectively (triangle).

indicated in the aforementioned Figs. 9a to 9c. All I-shaped test specimens but beams B107 and B108 failed due to shear in a very brittle manner. The aforementioned specimens exhibited severe diagonal web cracking leading to excessive yielding and sudden rupture of the shear reinforcement bars. Crushing of the diagonal compressive struts was not observed. Beams B107 and B108 exhibited a ductile bending failure mode leading to rupture of the prestressing strands. Typical experimentally observed failure modes of the presented test beams are shown in Figs. 10a to 10d. A number of observations can be made based on Figs. 9a to 9c and $10 \mathrm{a}$ to $10 \mathrm{~d}$ :

1. Prior to the onset of cracking, the stiffness in the elastic regime is comparable for all specimens with the same shear span and overall height. Indeed, prior to the occurrence of cracking, the response of the test specimens to the applied load is governed by the bending stiffness EI. Due to the comparable secant modulus of elasticity, refer to Table 1, and the negligible influence of the area of longitudinal reinforcement on the second moment of inertia, it can be concluded that the bending stiffness is similar for the reported test specimens.

2. The occurrence of cracks determines the transition between linear and nonlinear behaviour. All specimens exhibited both bending and web cracks. The load at which web cracks occurs, is function of the amount of prestressing and the concrete tensile strength respectively.

3. Specimens where shear reinforcement was provided and which failed in shear (B101-B102, B104-B105) exhibited a significant post-cracking stiffness and postcracking bearing capacity resulting in a brittle shear failure mode due to diagonal tension. Specimens B107 and B108 which failed in bending, show a highly ductile behaviour with a limited post-cracking bearing capacity. Finally, beams without shear reinforcement (B103, B106 and B109) failed immediately after the occurrence of the first inclined web crack.

The failure load and failure mode of each specimen is summarized and presented in Table 5. The experimentally determined failure load and failure mode can be compared to analytical predictions of the bearing capacity according to the shear design procedures outlined in Eurocode 2 (EC 2) (European Committee for Standardization 2004; Bureau for Standardisation NBN 2010). For the calculation of the shear capacity of a structural concrete member, a distinction is to be made between members with and without shear reinforcement. Structural concrete members with shear reinforcement are to be designed according to EC 2 using the variable angle truss model (VATM). This approach assumes that the behaviour of a structural concrete member near failure can be idealized by means of a parallel chord truss. The bottom and top flanges resist the applied bending moment whereas the combination of a compressive stress field with constant inclination and vertical tension bars resist the applied shear force. The design shear capacity $V_{R d}$ of a member with shear reinforcement is the minimum of the shear force required to obtain yielding of the shear reinforcement $V_{R d, s}$ and the shear force which causes crushing of the compressive struts $V_{R d, \max }$, refer to Eq. (1).

$$
V_{R d}=\min \left\{V_{R d, s}, V_{R d, \max }\right\}
$$

The expressions for $V_{R d, s}$ and $V_{R d, \max }$ can be derived from equilibrium conditions of the adopted truss model where the 

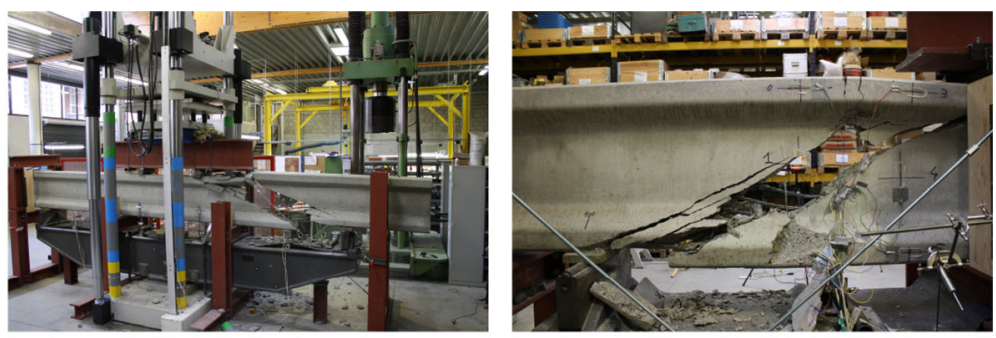

(a) Diagonal tension (DT) failure B102 (b) Diagonal tension failure B104

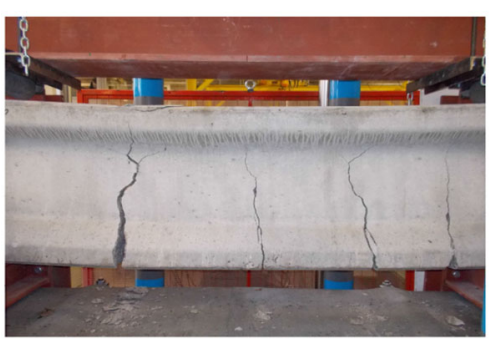

(c) Bending failure mode B107

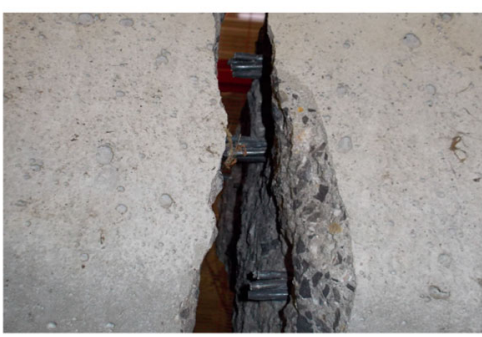

(d) Strand rupture B107

Fig. 10 Typical experimentally observed failure modes for the reported test specimens.

Table 5 Experimentally observed and analytically predicted failure load and failure mode.

\begin{tabular}{|c|c|c|c|c|c|c|}
\hline \multirow[t]{2}{*}{ Specimen } & \multicolumn{2}{|c|}{ Experiment } & \multicolumn{4}{|c|}{$\begin{array}{c}\text { Eurocode } 2 \text { (European Committee for Standardization 2004, Bureau for } \\
\text { Standardisation NBN 2010) }\end{array}$} \\
\hline & $\begin{array}{l}V_{u, \exp } \\
(\mathrm{kN})\end{array}$ & Failure mode & $\begin{array}{l}V_{\text {u,pred }} \\
(\mathrm{kN})\end{array}$ & $\begin{array}{c}V_{u, \text { bend }} \\
(\mathrm{kN})\end{array}$ & Failure mode & $\begin{array}{c}\frac{V_{u, e x p}}{V_{u, p r e d}} \\
(-)\end{array}$ \\
\hline B101 & 377.7 & $\mathrm{~S}-\mathrm{DT} \dagger$ & 158.1 & 412.2 & $S$ & 2.39 \\
\hline B102 & 321.6 & S-DT & 158.1 & 329.6 & $S$ & 2.03 \\
\hline B103 & 262.8 & S-DT & $243.3^{*}$ & 329.6 & $S$ & 1.08 \\
\hline B104 & 281.8 & S-DT & 135.2 & 406.6 & $S$ & 2.08 \\
\hline B105 & 251.2 & S-DT & 135.2 & 325.3 & $S$ & 1.86 \\
\hline B106 & 179.7 & S-DT & $206.9^{*}$ & 325.3 & $S$ & 0.87 \\
\hline B107 & 271.3 & B & 147.9 & 236.5 & $S$ & 1.83 \\
\hline B108 & 213.8 & B & 147.9 & 189.2 & $S$ & 1.45 \\
\hline \multirow[t]{3}{*}{ B109 } & 181.0 & S-DT & $197.0 *$ & 189.2 & B & 0.92 \\
\hline & & & & & $\frac{V_{u, \text { exp }}}{V_{u, p r e d}}$ & 1.61 \\
\hline & & & & & $\mathrm{COV}^{\mathrm{a}}$ & $55.4 \%$ \\
\hline
\end{tabular}

\footnotetext{
$\dagger$ Shear failure mode due to diagonal tension.

* Obtained using Eq. (12).

${ }^{\text {a }}$ Coefficient of Variation.
}

angle between the horizontal and the inclined compressive stresses is denoted by $\theta$, refer to Eqs. (2)-(3).

$$
\begin{aligned}
& V_{R d, s}=\frac{A_{s w}}{s} z f_{y w d} \cot \theta \\
& V_{R d, \max }=\frac{\alpha_{c w} v_{1} b_{w} z f_{c d}}{\cot \theta+\tan \theta}
\end{aligned}
$$

In Eqs. (2)-(3), $A_{s w} / s$ denotes the area of shear reinforcement per unit length, $z$ is the internal lever arm equal to $0.9 d$ whereas $f_{y w d}$ is the design value of the yield strength of the shear reinforcement bars. Factors $\alpha_{c w}$ and $v_{1}$ take into account the stress distribution of the compressive chord respectively the effect of lateral tensile straining on the ultimate compressive strength. The width of the web is denoted by $b_{w}$. The inclination angle $\theta$ can be chosen freely between certain limits as presented in Eq. (4).

$$
1 \leq \cot \theta \leq \cot \theta_{\max }
$$

The maximum value of $\cot \theta$, thus the minimum allowable value for the angle $\theta$ can be determined using Eq. (5) (Bureau for Standardisation NBN 2010). 


$$
\cot \theta_{\max }=2+\frac{0.15 \sigma_{c p} b_{w} d}{\frac{A_{s w}}{s} z f_{y w d}} \leq 3
$$

Equation (5) clearly indicates that for highly prestressed members (average normal stress due to prestressing $\sigma_{c p}$ ), a lower angle of inclination is allowed with a minimul value of $\theta=18.4^{\circ}$.

In the case of structural concrete members without shear reinforcement, a distinction has to be made between members cracked respectively uncracked due to the acting bending moment, refer to Eqs. (6)-(7).

$$
\begin{aligned}
V_{R d} & =V_{R d, c 1} \\
& =\left[\frac{0.18}{\gamma_{c}}\left(1+\sqrt{\frac{200}{d}}\right)\left(100 \frac{A_{s l}}{b_{w} d} f_{c k}\right)^{\frac{1}{3}}+0.15 \sigma_{c p}\right] b_{w} d \\
V_{R d} & =V_{R d, c 2}=\frac{I b_{w}}{S} \sqrt{f_{c t d}^{2}+\alpha_{l} \sigma_{c p} f_{c t d}}
\end{aligned}
$$

In the previous equations, $\gamma_{c}$ is a partial safety factor (equal to 1.5$), A_{s l}$ is the area of longitudinal tensile reinforcement, $I$ is the second moment of area whereas $S$ is the first moment of area. Finally, $f_{c t d}$ is the design value of the characteristic uni-axial concrete tensile strength. If Eqs. (1)-(7) are used to estimate the actual failure load, partial safety factors should be omitted and average material properties are to be used rather than characteristic or design values. Eqs. (2)-(3) and Eqs. (5)-(7) are then transformed to Eqs. (8)-(12).

$$
V_{R, s}=\frac{A_{s w}}{s} z f_{y m} \cot \theta_{\max }
$$

$$
\begin{aligned}
& V_{r, \text { max }}=\frac{\alpha_{c w} v_{1} b_{w} z f_{c m}}{\cot \theta_{\max }+\left(\cot \theta_{\max }\right)^{-1}} \\
& \cot \theta_{\max }=2+\frac{0.15 \sigma_{c p} b_{w} d}{\frac{A_{s w}}{s} z f_{y m}} \leq 3 \\
& V_{R, c 1}=\left[0.18\left(1+\sqrt{\frac{200}{d}}\right)\left(100 \frac{A_{s l}}{b_{w} d} f_{c m}\right)^{\frac{1}{3}}+0.15 \sigma_{c p}\right] b_{w} d \\
& V_{R, c 2}=\frac{I b_{w}}{S} \sqrt{\left(0.67 f_{c t m, f l}\right)^{2}+\alpha_{l} \sigma_{c p}\left(0.67 f_{c t m, f l}\right)}
\end{aligned}
$$

In Eq. (12), the mean value of the uni-axial tensile strength is written as a function of the experimentally determined mean flexural tensile strength. The adopted relation is given in Müller et al. (2013). The results of the aforementioned calculation using Eqs. (8)-(12) are also indicated in Table 5. The theoretical failure load required to obtain a bending failure mode, derived from a general plane section analysis $V_{u, b e n d}$, is also indicated in the aforementioned Table 5.

Based on the results presented in Table 5, the following observations and preliminary conclusions can be made:

1. In general, a poor correlation is found between the experimental results and analytical calculations according to EC 2 for all specimens apart for beams B103, B106 and B109 without shear reinforcement. Even if all partial safety factors are omitted and average material strength properties are used rather than characteristic or design values, an average experimental-to-predicted failure load ratio of 1.61 is found with a coefficient of variation $(\mathrm{COV})$ equal to $55.4 \%$.
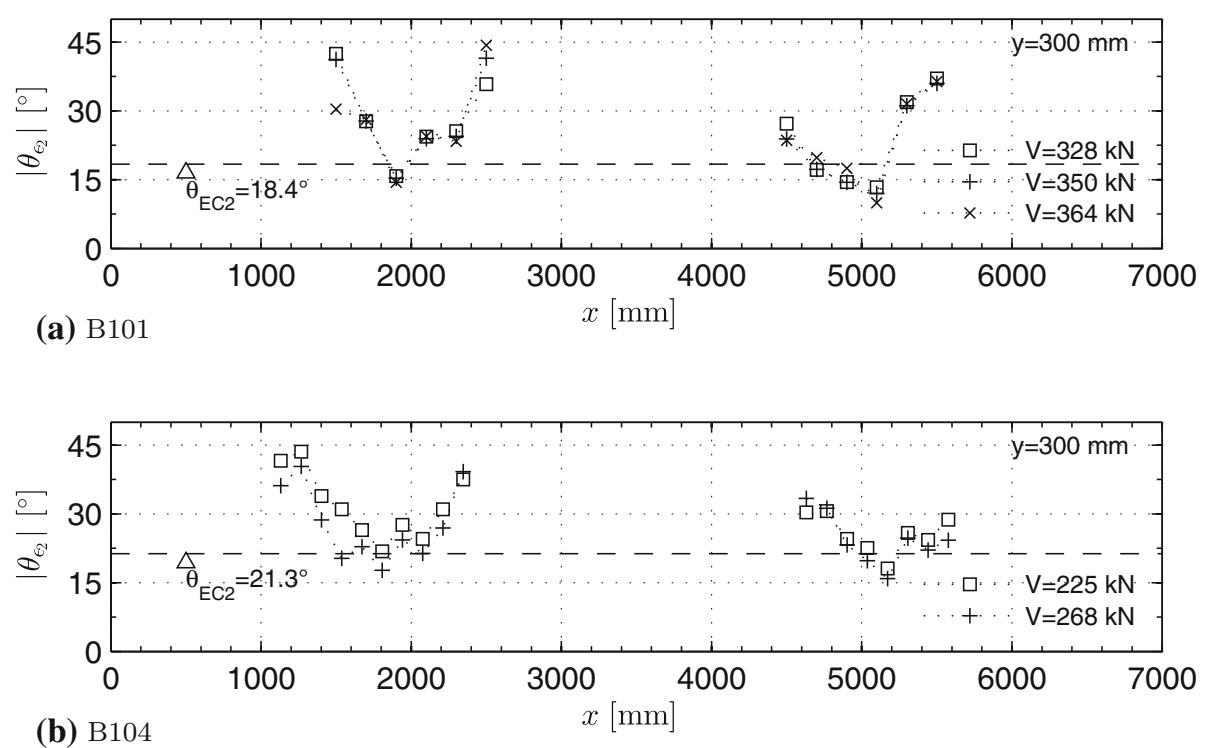

Fig. 11 Experimentally measured angle $\left|\theta_{\epsilon_{2}}\right|$ between the direction of the principal compressive strain $\epsilon_{2}$ as a function of the location along the $x$-axis and applied load for specimens a B101 (derived from Krypton K600 CMMs) and b B104 (derived from $3 \mathrm{D}-\mathrm{DIC}$ ). 


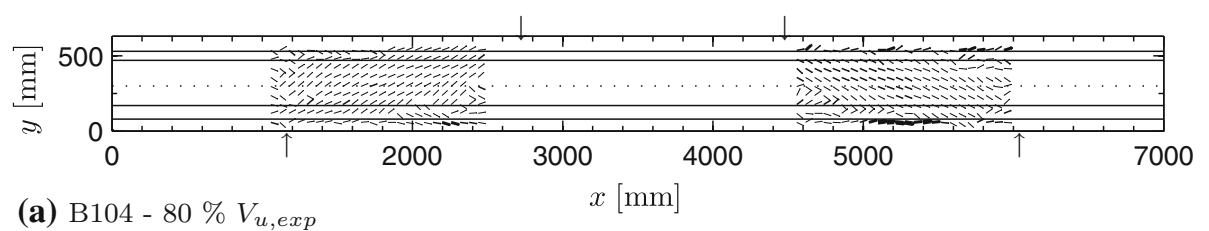

(a) $\mathrm{B} 104-80 \% V_{u, \exp }$

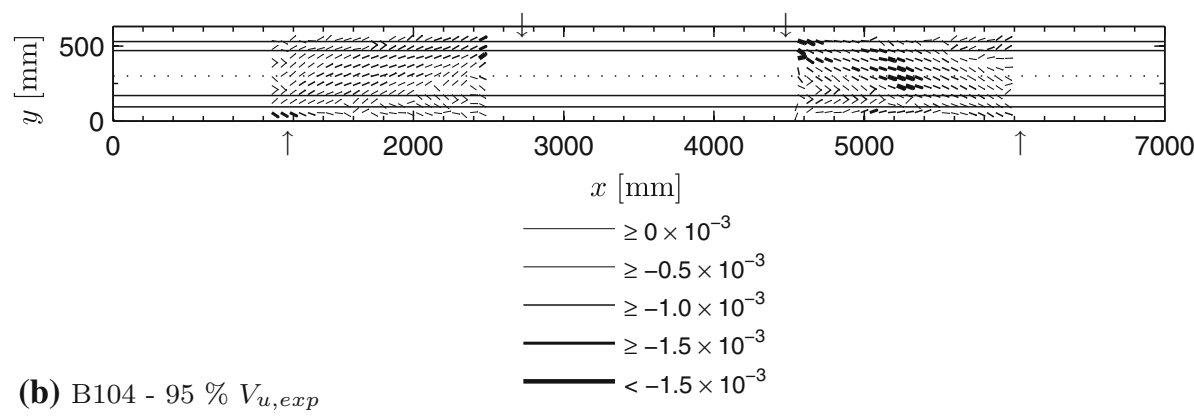

Fig. 12 Experimentally determined direction and magnitude of the principal compressive strain field $\epsilon_{2}$ of specimen B104 as a function of the surface coordinates and the applied load level (Note line where the angle $\left|\theta_{\epsilon_{2}}\right|$ was determined in Fig. 11b indicated with a dotted line).

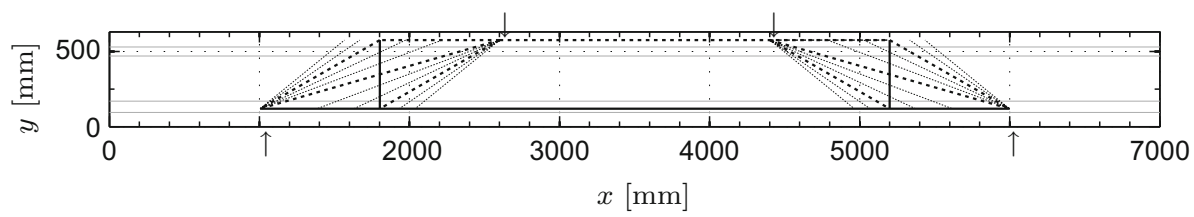

Fig. 13 Schematic representation of the identified mechanical behaviour of the presented test beams (Members in compression indicated with a dashed line, member in tension indicated with a solid line).

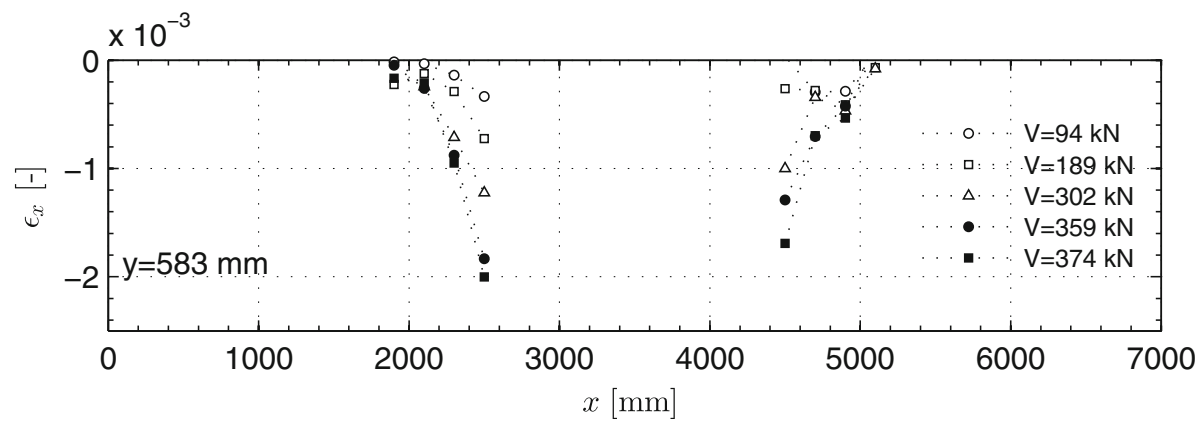

Fig. 14 Typical experimentally observed horizontal strain profile at the flange of specimen B101 as a function of the applied load and location along the longitudinal $x$-axis.

2. The failure mode is correctly predicted for all specimens apart for beams B107-B109. Specimens B107 and B108 failed due to bending despite having a lower shear capacity in comparison to the corresponding bending strength. Indeed, the experimental failure load correlates well with the theoretical load required to obtain the bending capacity for the aforementioned specimens. Moreover, the wrongly predicted failure mode for specimen B109 can be attributed to the small difference in the analytically calculated shear and bending capacity.

3. As expected, increasing the shear reinforcement ratio, increases the shear capacity (B102-B103, B105-B106, B108-B109).

4. Increasing the shear span-to-effective depth ratio while keeping all other investigated parameters constant, consistently decreases the experimentally observed shear failure load (B101-B102, B104-B105).

5. Increasing the prestressing force while keeping the longitudinal reinforcement ratio approximately constant, increases the shear capacity of specimens with (B101B104, B102-B105) and without shear reinforcement (B103-B106).

6. Decreasing the longitudinal reinforcement ratio while keeping the prestressing force constant does not significantly influence the failure load (B104-B07, B105B108 and B106-B109). However, the failure mode shifts from a brittle shear induced failure mode towards a more ductile bending induced failure mode for specimens with shear reinforcement. 
The found discrepancy between the experimentally observed and analytically calculated failure load in the case of prestressed concrete members with shear reinforcement is certainly to be further investigated. Therefore, the experimentally observed mechanical behaviour is assessed based on the acquired data of the optical(-numerical) measurement methods. Figure $11 \mathrm{a}, \mathrm{b}$ present the experimentally determined angle $\left|\theta_{\epsilon_{2}}\right|$ between the principal compressive strain $\epsilon_{2}$ with respect to the horizontal at mid-depth determined from the Krypton $\mathrm{K} 600 \mathrm{CMMs}$ respectively 3D-DIC as a function of the location along the $x$-axis and the applied load. The measured value for $\left|\theta_{\epsilon_{2}}\right|$ is compared to the adopted value for $\theta$ used for the presented strength calculations, refer to Table 5. Similar results were obtained for the remaining test specimens.

Figures $11 \mathrm{a}$ and $11 \mathrm{~b}$ indicate that the value of the experimentally determined angle $\left|\theta_{\epsilon_{2}}\right|$ in the middle of the shear span $(x=1800$ and $5200 \mathrm{~mm})$ correlates well with the adopted value of the angle $\theta$ in the presented shear strength calculations, refer to Table 5. However, the value of $\left|\theta_{\epsilon_{2}}\right|$ is not constant along the longitudinal $x$-axis of the specimen contrary to the assumption made by the VATM approach. Instead, a parabolic course of the angle $\left|\theta_{\epsilon_{2}}\right|$ is observed which does not tend to change significantly if the loading is furthermore increased. This observation if clarified by Figs. $12 \mathrm{a}$ and $12 \mathrm{~b}$ which presents the full-field magnitude and direction of the principal compressive strain field $\epsilon_{2}$ for specimen B104 as a function of the surface coordinates and the applied load. Similar results were observed for the remaining specimens where the DIC technique has been adopted.

Based on the direction and magnitude of the principal compressive strain field $\epsilon_{2}$ presented in Figs. 12a and 12b, it can be observed that a direct compression strut is developed between the support point and the load application point which carries a significant amount of the applied load. The remaining part of the applied load fans out towards the bottom of the specimen. A similar observation can be made for the support point load. The force in both aforementioned fan regions is equilibrated by the vertical force in the shear reinforcement elements. A schematic representation of the identified structural behaviour as presented in Figs. 12a and $12 \mathrm{~b}$ is depicted in Fig. 13. The identified structural behaviour as described above corresponds with the observed parabolic course of the direction of the principal compressive strain $\left|\theta_{\epsilon_{2}}\right|$. In view of the mechanical behaviour of the presented test specimens presented in Figs. 12a, 12b and 13, the experimentally observed failure mode should be interpreted as a splitting failure mode due to the forces in the fan regions.

Direct strut action is generally considered to be an important bearing mechanism for beams with a shear spanto-effective depth ratio less than or equal to 2.5 (Ramirez et al. 1998). However, the presented test beams were characterized by a shear span-to-effective depth ratio varying between 2.91 and 3.91, refer to Table 3. The identified structural behaviour, as presented in Figs. 12a, 12b and 13, provides a plausible explanation for the following experimentally observed phenomena.
1. The possibility of carrying the applied shear force by means of direct strut action significantly increases the shear carrying capacity in comparison to the shear capacity obtained using the variable angle truss model as proposed by Eurocode 2. This provides a possible explanation why the current sectional shear design provisions found in EC2 performed poorly in predicting the shear capacity of the presented prestressed concrete beams.

2. Figure 14 shows the typically observed profile of the horizontal strain $\epsilon_{x}$ at the top flange of the presented test beams. Figure 14 clearly shows that the horizontal strain at the top of the presented beams rapidly decreases to relatively low strains, and thus relatively low stresses, away from the loading point. Due to the inclined strut action, it is indeed expected that low strain values occur at the top of the specimen near the support point.

\section{Conclusions}

This paper aims to investigate on the use of advanced optical(-numerical) measurement methods for the mechanical analysis of shear-critical prestressed concrete beams. Therefore, an experimental program consisting of nine fullscale prestressed I-shaped beams was drafted. The main investigated parameters were the amount of prestressing, the amount of longitudinal reinforcement and shear reinforcement and the shear span-to-effective depth ratio respectively. All specimens were subjected to a load-controlled four-point bending test until failure. During the experimental research, the use of two advanced optical(-numerical) measurement methods, i.e. $3 D$ coordinate measurement machines (CMM) and stereo-vision digital image correlation (3D-DIC), was explored. Firstly, the experimental setup was elaborated in detail. Specifically in the case of the DIC technique, a novel technique to apply numerically synthesised strain sensor patterns, i.e. speckle patterns, in a controlled way was presented. The presented technique allows for the application of tailor-made strain sensor patterns to virtually any given object's surface. A reference measurement was performed in unloaded state to asses the measurement precision. Both techniques were found to be comparable in terms of displacement and strain resolution. The maximum standard deviation of the in-plane displacements was equal to approximately $20 \times 10^{-3} \mathrm{~mm}$ for the CMMs whereas a value of approximately $30 \times 10^{-3} \mathrm{~mm}$ was found for the DIC technique. Moreover, the expected value of the strains occurring during the experiments well exceeded the observed noise levels on the in-plane horizontal and vertical strains. It can thus be concluded that both techniques are well suited for assessing the structural behaviour of the reported test specimens. However, due to the brittle and highly energy releasing failure modes observed during the tests on specimens failing in shear, the DIC technique is preferred over the CMM technique since the latter technique requires relatively expensive IR LED sensors to be glued 
onto the concrete side surface which can sustain damage at the moment of failure.

All specimens were designed to fail in shear. However, seven specimens failed in a brittle manner due to shear (diagonal tension failure mode) whereas two specimens failed due to bending in a ductile manner. The experimental results were compared to analytical calculations according to the current design procedures found in Eurocode 2 (EC 2). Based on the work presented in this paper, it can be concluded that EC 2, adopting the variable angle truss model, in general significantly underestimates the experimentally determined failure load. Omitting all partial safety factors and using average material strength properties rather than characteristic values resulted in an average experimental-topredicted failure load ratio equal to 1.61 (coefficient of variation equal to $55.4 \%$ ). Based on the extensive amount of experimental displacement and deformation data, it was found that the applied load was primarily carried by means of a direct compression strut in combination with fan regions contrary to the model adopted by EC 2 which assumes that a compression field with constant inclination along the member's axis is developed. The identified structural behaviour for the reported test specimens can be used to optimize current shear design provisions as proposed by codes of practice.

\section{Open Access}

This article is distributed under the terms of the Creative Commons Attribution 4.0 International License (http://creativecommons.org/licenses/by/4.0/), which permits unrestricted use, distribution, and reproduction in any medium, provided you give appropriate credit to the original author(s) and the source, provide a link to the Creative Commons license, and indicate if changes were made.

\section{References}

American Concrete Institute. (2011). Aci 318-11 building code requirements for structural concrete and commentary.

Balázs, G. L. (2010). A historical review of shear. In V. Sigrist, F. Minelli, G. Plizzari, \& S. Foster (Eds.), Bulletin 57: Shear and punching shear in RC and FRC elements (pp. 1-13). Lausanne, Switzerland: Fédération Internationale du Béton (fib).

Bossuyt, S. (2012). Optimized patterns for digital image correlation. In Proceedings of the SEM International Conference and Exposition on Experimental and Applied Mechanics, volume 3: Imaging Methods for Novel Materials and Challenging Applications, Costa Mesa, CA, USA, Society for Experimental Mechanics.

Bureau for Standardisation NBN. (2009a). Nbn en 12390-3. Bureau for Standardisation NBN. (2009b). Nbn en 12390-5. Bureau for Standardisation NBN. (2010). Nbn en 1992-1-1 anb. Bureau for Standardisation NBN. (2014). Nbn en 12390-13.

Burg, J., Peeters, K., Natsakis, T., Dereymaeker, G., Vander Sloten, J., \& Jonkers, I. (2013). In vitro analysis of muscle activity illustrates mediolateral decoupling of hind and mid foot bone motion. Gait and Posture, 38(1), 56-61.

Canadian Standards Association. (2004). Csa a23.3 design of concrete structures (csa a23.3-04), 2004.

Collins, M. P. (2010). Improving analytical models for shear design and evaluation of reinforced concrete structures. In V. Sigrist, F. Minelli, G. Plizzari, \& S. Foster (Eds.), Bulletin 57: Shear and punching shear in RC and FRC elements (pp. 77-92). Lausanne, Switzerland: Fédération Internationale du Béton (fib).

Cooreman, S., Debruyne, D., Coppieters, S., Lecompte, D., \& Sol, H. (2008). Identification of the mechanical material parameters through inverse modelling (pp. 337-342). NonDestructive Testing: Emerging Technologies in.

Cooreman, S., Lecompte, D., Sol, H., Vantomme, J., \& Debruyne, D. (2007). Elasto-plastic material parameter identification by inverse methods: Calculation of the sensitivity matrix. International Journal of Solids and Structures, 44(13), 4329-4341.

De Roeck, G., Wens, L., \& Jacobs, S. (2004). 3d static and dynamic displacement measurements by a system of three linear ccd-units. In P. Sas \& M. De Munck (Eds.), International Conference on Noise and Vibration Engineering (ISMA) (pp. 2289-2300), Leuven, Belgium: KU Leuven.

Deconinck, F., Desmet, W., \& Sas, P. (2004). Increasing the accuracy of mdof road reproduction experiments: Calibration, tuning and a modified twr approach. In P. Sas \& M. De Munck (Eds.), International Conference on Noise and Vibration Engineering (ISMA) (pp. 709-722), Leuven, Belgium: KU Leuven.

Destrycker, M. (2012). Experimental validation of residual stress simulations in welded steel tubes with digital image correlation. PhD thesis, KU Leuven, Department of Civil Engineering.

European Committee for Standardization (CEN). (2004). Eurocode 2: Design of concrete structures-part 1-1: General rules and rules for buildings.

Fédération Internationale du Béton (fib). (2010). Shear and punching shear in RC and FRC elements-Workshop 15-16 October 2010, Salò (Italy), volume 57 of Bulletin, Lausanne (Switzerland).

Ivanov, D., Ivanov, S., Lomov, S., \& Verpoest, I. (2009). Strain mapping analysis of textile composites. Optics and Lasers in Engineering, 47(3-4), 360-370.

Jeong, J.-P., \& Kim, W. (2014). Shear resistant mechanism into base components: Beam action and arch action in shearcritical rc members. International Journal of Concrete Structures and Materials, 8(1), 1-14.

Knauss, W. G., Chasiotis, I., \& Huang, Y. (2003). Mechanical measurements at the micron and nanometer scales. $\mathrm{Me}$ chanics of Materials, 35(3-6), 217-231.

Lantsoght, E., van der Veen, C., Walraven, J., \& de Boer, A. (2013). Shear assessment of reinforced concrete slab bridges. Structural Engineering International, 4, 418-426.

Lava, P., Cooreman, S., Coppieters, S., De Strycker, M., \& Debruyne, D. (2009). Assessment of measuring errors in dic using deformation fields generated by plastic fea. Optics and Lasers in Engineering, 47(7-8), 747-753. 
Lava, P., Cooreman, S., \& Debruyne, D. (2010). Study of systematic errors in strain fields obtained via dic using heterogeneous deformation generated by plastic fea. Optics and Lasers in Engineering, 48(4), 457-468.

Lava, P., Coppieters, S., Wang, Y., Van Houtte, P., \& Debruyne, D. (2011). Error estimation in measuring strain fields with dic on planar sheet metal specimens with a non-perpendicular camera alignment. Optics and Lasers in Engineering, 49(1), 57-65.

Lecompte, D. (2007). Elasto-Plastic material parameter identification by inverse modeling of static tests using digital image correlation. $\mathrm{PhD}$ thesis, Vrije Universiteit Brussel, Department of Mechanics of Materials and Constructions.

Müller, H., Breiner, R., Anders, I., Mechterine, V., Curbach, M., Speck, K., et al. (2013). Code-type models for concrete bahviour (Vol. 70)., Bulletin Lausanne, Switzerland: Fédération Internationale du Béton.

Nakamura, E., Avendano, A. R., \& Bayrak, O. (2013). Shear database for prestressed concrete members. ACI Structural Journal, 110(6), 909-918.

Ramirez, J. A., et al. (1998). Recent approaches to shear design of structural concrete. Journal of Structural EngineeringAsce, 124(12), 1375-1417.

Sas, G., Blanksvard, T., Enochsson, O., Taljsten, B., \& Elfgren, L. (2012). Photographic strain monitoring during full-scale failure testing of ornskoldsvik bridge. Structural Health Monitoring-an International Journal, 11(4), 489-498.

Srikar, G., Anand, G., \& Suriya Prakash, S. (2016). A study on residual compression behavior of structural fiber reinforced concrete exposed to moderate temperature using digital image correlation. International Journal of Concrete Structures and Materials, pp. 1-11.

Sun, S. (2007). Shear behavior and capacity of large-scale prestressed high-strength concrete bulb-tee girders. $\mathrm{PhD}$ thesis, University of Illinois at Urbana-Champaign, Department of Civil and Environmental Engineering.

Sutton, M. A., Orteu, J. J., \& Schreier, H. W. (2009). Image correlation for shape, motion and deformation measurements: basic concepts, theory and applications. New York, NY: Springer.

Valerio, P., Ibell, T., \& Darby, A. P. (2011). Shear assessment of prestressed concrete bridges. Proceedings of the Institution of Civil Engineers-Bridge Engineering, 164(4), 195-210.

Van Paepegem, W., Shulev, A. A., Roussev, I. R., De Pauw, S., Degrieck, J., \& Sainov, V. C. (2009). Study of the deformation characteristics of window security film by digital image correlation techniques. Optics and Lasers in Engineering, 47(3-4), 390-397.

Wang, Y., Lava, P., Debruyne, D., \& Van Houtte, P. (2011). Error estimation of dic for heterogeneous strain states. Advances in Experimental Mechanics VIII, 70, 177-182. 